\title{
Death on the waiting list for cardiac surgery in the Netherlands in 1994 and 1995
} J Plomp, W K Redekop, F W Dekker, T R van Geldorp, M M P Haalebos, G Jambroes,
J H Kingma, F Zijlstra, J G P Tijssen
Department of Clinical Epidemiology and Biostatistics, Academic Medical Center, University of Amsterdam, PO Box $22700,1100 \mathrm{DE}$ Amsterdam, Netherlands J Plomp

W K Redekop

F W Dekker

J G P Tijssen

Department of Cardiology, St

Antonius Hospital, Nieuwegein,

Netherlands

J Plomp

J H Kingma

Department of Thoracic Surgery, Hospital De

Klokkenberg, Breda, Netherlands

T R van Geldorp

Department of Thoracic Surgery, De Weezenlanden Hospital, Zwolle, Netherlands M M P Haalebos

Department of Cardiology, De Weezenlanden

Hospital

F Zijlstra

Heart and Lung Institute, University

Hospital, Utrecht,

Netherlands

G Jambroes

Correspondence to: Professor Tijssen.

Accepted for publication 14 September 1998

\begin{abstract}
Objective-To describe the causes and circumstances of death regarding patients who died in 1994 and 1995 while on a waiting list for cardiac surgery in the Netherlands.

Design-Retrospective multicentre case study.

Setting-11 Dutch cardiac surgery centres.

Patients-All patients reported as dying while on the waiting list for cardiac surgery in 1994 and 1995.

Main outcome measures-Classification of death by an independent adjudication committee into "erroneously reported", "waiting list related" or "not waiting list related". Death was judged as "waiting list related" if the clinical course would have been substantially different if there had been unrestricted surgical capacity.

Results-138 and 129 deaths were reported in 1994 and 1995, respectively. 43 deaths $(16 \%)$ were considered as erroneously reported. 181 of the remaining 224 cases were adjudicated as waiting list related. Median time from acceptance for surgery to death was 35 days (interquartile range 14-75 days). 97 of 181 deaths occurred within six weeks following addition to the waiting list. The estimated incidence of death ranged from 1.33 per 1000 patient-weeks during weeks $2-4$ to 0.68 per 1000 patient-weeks after 12 weeks. Conclusions-The causes and circumstances of death are waiting list related for approximately 100 patients per year in the Netherlands. At least half of the deaths may occur within the first six weeks. Waiting lists for cardiac surgery engender high risks for the patients involved.

(Heart 1999;81:593-597)
\end{abstract}

Keywords: waiting lists; heart surgery; mortality; coronary bypass surgery

Restricted medical facilities and restricted manpower usually mean that patients have to wait for their medical care. Consequently in the Netherlands, as in countries such as the United Kingdom and Canada, there is a waiting list for cardiac surgery. However, waiting for surgery introduces an increased risk of death. ${ }^{12}$ To minimise this risk of death, the patient's need for surgery is assigned a certain priority and the patient is subsequently placed at one of several points along the queue.
If the general goal in a waiting list environment is to reduce further the risk of death in a cost efficient and equitable manner, relevant data are required. While it is known that patients die while awaiting cardiac surgery in the Netherlands, the actual frequency of death as well as their causes and circumstances remains unknown. We performed this study to investigate the number of patients who died in the years 1994 and 1995, and their characteristics. The objective of this study was to determine if the cause of death was related to the waiting list and therefore could have been avoided if there had been unrestricted operating capacity.

\section{Patients and methods}

All 13 cardiac surgery centres in the Netherlands expressed a willingness to participate in this project. Of these 13, two institutions were excluded because data were unavailable for reasons unrelated to the objectives of this study. The profiles of these two centres did not differ from those of the 11 centres included. Before starting this study, we sought and received approval by the medical ethics committee of the Academic Medical Center, Amsterdam.

All patients who died in 1994 or 1995 after being assigned to a waiting list for cardiac surgery in the Netherlands constituted the population for our study. To that end, cases of death were identified from local registries. Most of the participating institutions maintain a computerised waiting list as well as a record of any patients who die while awaiting cardiac surgery. All data in the medical records were checked by hand and when the medical record was incomplete we consulted first the referring cardiologist and then the general practitioner. We excluded any patients who had been proposed for surgery but had not yet been accepted.

\section{PATIENT CHARACTERISTICS}

For every patient we recorded the type of surgery requested (coronary artery bypass graft (CABG), heart valve surgery, combined $\mathrm{CABG} /$ valve surgery, or other surgery) and the presence of risk factors such as smoking, obesity, and previous cardiac surgery. We also recorded the interval between acceptance for surgery and death as well as the location of death. Finally, we recorded the priority for surgery at time of acceptance. All institutions assign each patient's surgery to one of the following priorities: 1 "urgent" (within 14 days); 2 "soon" (less than 6-8 weeks); and 3 
Table 1 Reported cases of death while waiting for cardiac surgery in the Netherlands

\begin{tabular}{lrrr}
\hline & 1994 & 1995 & Total \\
\hline Reported cases of death & 138 & 129 & 267 \\
Excluded & 22 & 21 & 43 \\
Remaining deaths & 116 & 108 & 224 \\
Waiting list unrelated death & 26 & 17 & 43 \\
Waiting list related death $\dagger$ & 90 & 91 & 181
\end{tabular}

^Erroneously reported; †Death was considered waiting list related if the patient would not have died at that time if there had been unrestricted operating capacity.

Table 2 Causes of death when death was considered waiting list related $(n=181)$

\begin{tabular}{lll}
\hline Category & Specific cause & Frequency \\
\hline Cardiac & $\begin{array}{l}\text { Sudden death without preceding } \\
\quad \text { symptoms }\end{array}$ & 86 \\
& Sudden death with preceding & 51 \\
$\quad$ symptoms & \\
& Acute myocardial infarction $<30$ & 20 \\
$\quad$ days before death & \\
& Heart failure & 15 \\
& Found dead & 3 \\
& Cerebrovascular accident & 2 \\
Non-cardiac & Rupture aneurysm aortae & 4
\end{tabular}

^Defined as enzyme elevation over two times normal values.

"delayed" (end of the waiting list). The rules used for assigning priority follow those outlined by Suttorp et al, with the key determinants for deciding on priority being extent of coronary artery disease, presence of left ventricular dysfunction, severity of anginal symptoms, and response to medical therapy. ${ }^{1}$ However, the prioritisation criteria may be interpreted differently from centre to centre.

The cause of death was divided into cardiac and non-cardiac, where every death was considered cardiac unless another cause was specified. Cardiac deaths were divided into: a) cerebrovascular death; b) sudden death with or without preceding symptoms less than 24 hours before death; c) myocardial infarction less than 30 days before death; d) heart failure; and e) found dead. When death could be classified into more than one of these categories, it was classified into the category appearing first in the list.

\section{ADIUDICATION OF DEATHS}

An adjudication committee consisting of three cardiologists and two cardiac surgeons reviewed all reported deaths and divided them into three categories: "erroneously reported"; "not waiting list related"; and "waiting list related". A death was considered erroneously reported when: a) it did not occur in 1994 or

Table 3 Characteristics of patients with a waiting list related death by initially assigned priority for surgery

\begin{tabular}{lllll}
\hline & $\begin{array}{l}\text { Priority 1 } \\
\text { ("urgent”) } \\
(n=25)\end{array}$ & $\begin{array}{l}\text { Priority 2 } \\
\text { ("soon”) } \\
(n=80)\end{array}$ & $\begin{array}{l}\text { Priority 3 } \\
\text { ("delayed") } \\
(n=76)\end{array}$ & $\begin{array}{l}\text { Total } \\
(n=181)\end{array}$ \\
\hline Male sex (\%) & 68 & 74 & 74 & 73 \\
Mean (SD) age (years) & $72(9)$ & $67(9)$ & $66(9)$ & $67(9)$ \\
Mean (SD) body mass index* & $26(4)$ & $26(4)$ & $27(5)$ & $26(4)$ \\
Smoked within the past 3 years (\%) & 25 & 51 & 45 & 45 \\
$\begin{array}{l}\text { Previous infarction (\%) } \\
\text { Previous heart surgery or PTCA (\%) }\end{array}$ & 56 & 43 & 51 & 48 \\
Coronary disease & 24 & 16 & 8 & 14 \\
$\quad$ Left main or three vessel disease (\%) & 68 & 63 & 61 & 62 \\
$\quad$ Left ventricular ejection fraction < 40\% (\%) & 24 & 25 & 16 & 21 \\
\hline
\end{tabular}

${ }^{\star}$ Body mass index $=$ weight $(\mathrm{kg}) /(\text { height }(\mathrm{m}))^{2}$; PTCA, percutaneous transluminal coronary angioplasty.
1995; b) the patient had suffered a thorax trauma; or c) the patient had been waiting for a heart transplantation. For each of the remaining deaths, the following question was asked: "Would this patient have died at this time and from this cause if there had been unrestricted operating capacity?". If the answer was "no" or if the doctor or patient had delayed the operation, the death was considered unrelated to the waiting list. If the answer was "yes" or if there was doubt about the answer (for example, cerebrovascular accident while waiting for valve surgery), the death was considered "waiting list related". We performed subsequent analyses using the patients whose deaths were considered waiting list related.

\section{CALCULATION OF INCIDENCES}

In the Netherlands all cardiac surgery institutions must report annually in November to the Dutch registration bureau for cardiac surgery (BHN) the sex, type of surgery, and waiting time of the last 100 consecutively operated patients. Using the 1994 data from this source, we could calculate the number of patientweeks seen for 971 patients. We used these results to estimate the total number of patientweeks spent on the waiting list for the 11 centres studied in 1994 and 1995. Incidences were calculated by dividing the total number of deaths by the estimated number of patientweeks. Apart from the overall incidence, we also calculated incidences for specific time periods. The incidences by type of procedure (CABG, valve, etc) were estimated using the distribution of procedures performed in the 11 centres in $1994^{3}$ and the total number of procedures carried out in these centres in 1994 and 1995.

\section{Results}

Table 1 shows all deaths reported by the 11 participating cardiac surgery centres. Forty three deaths were excluded because they were considered erroneously reported. The adjudication committee classified 181 deaths as being related to the waiting list. "Waiting list related deaths" were mainly cases of sudden death with or without preceding symptoms (table 2). The location of death was distributed as follows: $20 \%$ in the hospital after acceptance for surgery and during initial hospitalisation; $26 \%$ in the hospital after readmission; and $54 \%$ at home. We divided the patients into groups based on their initially assigned priority. Examination of the characteristics of these patients (table 3 ) revealed that the priority for surgery was not strongly related to many of these characteristics. One exception was the lower percentage of recent smokers in the highest priority group. Another exception was the frequency of previous heart surgery or balloon angioplasty procedure. Specifically, the percentage of patients with previous surgery increased as the urgency for surgery increased $\left(\chi^{2}\right.$ test for linear trend $\left.=4.785, \mathrm{p}=0.029\right)$. This may simply reflect general differences in the frequency of previous surgery or percutaneous transluminal coronary angioplasty between the priority groups. Regarding disease 
Table 4 Distribution of procedures planned for patients with a waiting list related death compared with the distribution of all cardiac procedures performed in the Netherlands (1994)

\begin{tabular}{lccll}
\hline Type of procedure & $\begin{array}{l}\text { Waiting list related } \\
\text { deaths }(n=181)\end{array}$ & $\begin{array}{l}\text { Netherlands* } \\
(n=13717)\end{array}$ & $\begin{array}{l}\text { Absolute risk } \\
\text { (estimate) }\end{array}$ & Relative risk (95\% CI; p value) \\
\hline CABG surgery & $110(61 \%)$ & $72 \%$ & 0.006 & 1.00 \\
Valve surgery & $34(19 \%)$ & $15 \%$ & 0.009 & $1.48(1.01-2.18 ; 0.046)$ \\
CABG and valve surgery & $34(19 \%)$ & $5 \%$ & 0.027 & $0.45(3.04-6.51 ;<0.001)$ \\
Other & $3(1 \%)$ & $8 \%$ & 0.002 & $0.25(0.08-0.77 ; 0.007)$ \\
\hline
\end{tabular}

*Adapted from reference 3 .

CABG, coronary artery bypass graft surgery.

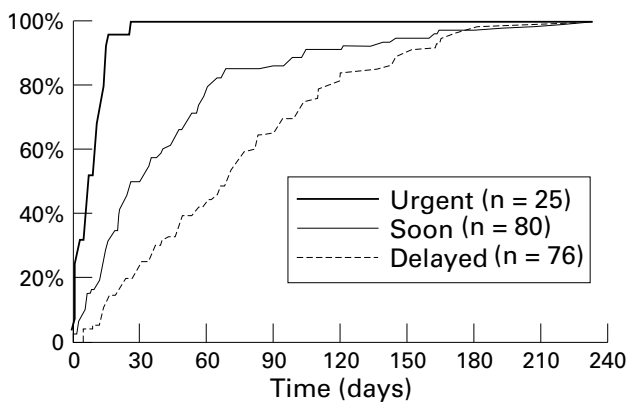

Figure 1 Cumulative frequency of waiting list related deaths by priority for surgery.

Table 5 Incidence of waiting list related deaths stratified by time on waiting list (Netherlands 1994 and 1995)

\begin{tabular}{llll}
\hline & $\begin{array}{l}\text { Number of } \\
\text { deaths }\end{array}$ & $\begin{array}{l}\text { Estimated } \\
\text { number of } \\
\text { patient weeks }\end{array}$ & $\begin{array}{l}\text { Incidence (per } \\
\text { 1000 patient } \\
\text { weeks) }\end{array}$ \\
\hline Total & 181 & 199637 & 0.91 \\
$<2$ weeks & 43 & 39359 & 1.09 \\
2-4 weeks & 37 & 27858 & 1.33 \\
4-6 weeks & 17 & 23068 & 0.74 \\
6-12 weeks & 45 & 51594 & 0.87 \\
$>12$ weeks & 39 & 57758 & 0.68 \\
\hline
\end{tabular}

severity, there was a slightly higher percentage of patients with a left ventricular ejection fraction of less than $40 \%$ in the two higher priority groups 1 and 2 .

Table 4 shows the distribution of the type of surgery planned for patients who died a waiting list related death and the distribution of all types of surgery conducted in the Netherlands. Estimates of the risks and relative risks for the different subgroups are also shown in this table. Examination of these risks suggests that patients waiting for CABG surgery experienced a lower risk of waiting list related death than patients scheduled to receive valve or combination surgery, and a higher risk of death than patients accepted for other cardiac procedures.

Figure 1 shows the time from acceptance for surgery to death in relation to the originally assigned priority. In priority group 1 ("urgent") deaths occurred after a short waiting time, the median time to death being eight days (range 0-27 days). In the two other priority groups, however, there were also cardiac deaths within days following acceptance for surgery. Moreover, in priority group 2 ("soon"), $60 \%$ of the deaths occurred within the first six weeks, and in priority group 3 ("delayed"), $67 \%$ of the deaths occurred within the first three months.

The incidence density for mortality (table 5) appears to remain unchanged for the first four weeks and appears to decrease thereafter. Particularly noteworthy is the fact that 97 of the
181 deaths $(54 \%)$ occurred within the first six weeks following acceptance for surgery.

\section{Discussion}

Using data from 11 of the 13 cardiac surgery centres in the Netherlands, we identified 181 waiting list related deaths in the years 1994 and 1995. Based on the number of procedures conducted over these years in all 13 centres, we estimate that approximately 100 waiting list related deaths occur per year in the Netherlands.

We can draw a number of conclusions based on the results of this study. To begin with, persons on the waiting list for cardiac surgery show a high incidence of waiting list related deaths. Juul-Möller et al observed 46 deaths in their placebo study group of 1026 stable angina pectoris patients over an estimated median follow up period of 50 months. ${ }^{4}$ Such an incidence of 11 deaths per 1000 patient-years is much lower than the incidence observed in the present study (42 deaths per 1000 patient years, or 0.81 deaths per 1000 patient-weeks). Studies by Suttorp et al and Naylor et al have also noted that waiting for heart surgery is associated with an increased risk of fatal events. ${ }^{12}$ Naylor et al found a risk of mortality of $0.4 \%$ (31/8247) among patients waiting for isolated CABG surgery, ${ }^{2}$ and concluded that this risk was too high, considering that the "overall in-hospital mortality after bypass surgery is less than $4 \%$ ". In reaction to the Naylor et al article, Billings et al reported two sets of results, ${ }^{5}$ both of which showed much higher risks of mortality than those reported by Naylor et al. ${ }^{2}$ One set of results was found in a retrospective study at a UK hospital (1988 to 1993) where the overall risk of mortality was $1.65 \%(57 / 3453)$ and the incidence was estimated to be 4.1 deaths per 100 patientyears (or 0.79 deaths per 1000 patient-weeks). The other set of results was based on one UK surgeon's waiting list: an overall risk of mortality of $2.4 \%(12 / 496)$ and an incidence of 6.3 deaths per 100 patient-years (or 1.21 deaths per 1000 patient-weeks). Silber et al reported that 15 of 1125 patients died (1.3\%) while waiting for $\mathrm{CABG}$ or $\mathrm{CABG} /$ valve surgery in Germany. ${ }^{6}$ When we included patients waiting for CABG surgery only, we found a waiting list mortality risk of $0.6 \%$. In contrast, patients waiting for valve or combined CABG/valve surgery experienced a risk of death of $1.4 \%$. To put these risks into perspective, it is worthwhile examining what the risks of mortality are during and following surgery. One hospital in the Netherlands has reported a perioperative mortality rate of $1.2 \%$ for a group 
of 1041 patients undergoing CABG surgery. ${ }^{78}$ Moreover, the risk of mortality (including perioperative death) by the end of the first year following surgery was $3.2 \%$.

We found that the incidence of deaths while waiting for surgery varied. Specifically, the incidence of waiting list related deaths appeared higher over the initial few weeks on the waiting list than over the weeks thereafter (table 5). For example, the incidence within the first month was 1.19 deaths per 1000 patientweeks while the incidence thereafter was 0.76 deaths per 1000 patient-weeks.

In addition to the increased incidence in the first weeks of waiting for surgery, a large percentage of the waiting list related deaths $(54 \%)$ occurred within the first six weeks on the waiting list. The recommended "planning reserve" (or waiting time) in the Netherlands is no longer than six weeks. ' Consequently, adherence to this suggested guideline would avoid only half of the waiting list related deaths. If a greater percentage of these deaths is to be avoided, the planning reserve should be shortened as much as is reasonably possible and should certainly be less than six weeks. Silber et $a l$ in Germany also found that deaths occurred early, all of the 15 observed deaths taking place within four weeks after diagnostic catheterisation. ${ }^{6}$ They concluded that surgery "must be offered within a week after diagnostic angiography, even for 'elective' cases." However, a reduction in the planning reserve amounts to a shortening in the average waiting time. This strategy is inefficient and wasteful if there is a possibility to identify beforehand those patients who will die a waiting list related death. In other words, a general reduction in waiting time is to be introduced only when it is not possible to predict which patients will suffer a waiting list related death. This begs the question of whether we are able to pick out those patients who are at the greatest risk of dying a waiting list related death and place them at the top of a waiting list. While it is not possible to predict perfectly who will die a waiting list related death, there is enough knowledge available to be able to categorise patients into different priority groups.

This concept of prioritisation is in essence the rationale behind triage, although the criteria to be used in prioritisation encompass more than simply the estimated risk of a waiting list related death. ${ }^{10}$ Clinicians use a set of guidelines to differentiate patients in greater medical need from those patients in less need. ${ }^{11}{ }^{12}$ Indeed, this ability is advanced since several categories are to be found in the triage schema. For example, in the Netherlands, three general categories exist for use with patients accepted to the waiting list, while four categories are used in the only centre serving the two Canadian provinces of Nova Scotia and Prince Edward Island. ${ }^{11}$

Since waiting lists cannot be eliminated, and since it is not possible to predict perfectly who will die a waiting list related death, we must accept the fact that waiting for surgery is unavoidable. If we want to introduce and maintain fairness in the system, how is this possible in a waiting list environment? One way to obtain fairness in the system is to ensure that each patient will experience the same risk of a waiting list related death as everyone else. Risk of death has two components: incidence density, which should be equal for all patients added to the same priority group; and the length of time on the waiting list. Adjusting one or both of these components can change the frequency of waiting list related deaths in the total population. First, one can reorganise the priority groups and thereby influence the incidence densities in the groups. The aim in this case would be to separate further the so called high risk patients (higher incidence density) from the low risk patients (lower incidence density). Alternatively, one can shorten or lengthen the average waiting time in a particular priority group in order to equalise the observed risks in the different priority groups. Indeed, this idea corresponds with what is seen in existing waiting lists. Namely, patients with the greatest need (highest incidence of problems including death) wait for the shortest period of time while those with the least need (lowest incidence) wait longer. Nevertheless, it would be advantageous to develop a quantitative method of achieving what queuing programmes presently aim at, much in the same way that previous studies have attempted to quantify the priority for surgery. ${ }^{13}$

If increased resources were to be made available to reduce waiting times, how might waiting times best be reduced for the different priority groups? If equality in risk is desired, the degree of reduction in waiting time will vary between the different priority groups and will depend on the differences in incidence density. However, if we want to use a quantitative approach to solving this, we need incidence data for the different priority groups. Incidences over the waiting time would also be valuable since we found that the incidence of waiting list related deaths varied between the time periods (table 5). Currently, a national database for cardiac interventions is being developed by the counselling committee for cardiac surgery in the Netherlands (Begeleidingscommissie Hartchirurgie Nederland). Thus, in several years' time it will be possible to compare in detail the incidences of waiting list related death in the different priority groups. However, based on the results of the present study, what can be said about the impact of reducing the waiting time or adjusting the prioritisation schema? We can answer this by examining how soon after acceptance deaths occurred in relation to the assigned priority for surgery (fig 1) and in relation to the type of surgery. If the maximum waiting times for patients assigned to priorities 2 and 3 had been shortened to two weeks and six weeks, respectively, and if all valve operations had been given a priority of 1 or 2 , this would have prevented $65 \%$ of the waiting list related deaths (118/181).

Another strategy to avoid death would be to provide emergency surgery to any patient showing symptoms that could lead to death. However, the distribution of the causes of death shown in table 2 indicates that the 
percentage of deaths avoidable using this strategy is rather low. That is, heart failure, the only type of death that involves the onset of symptoms well in advance of death (more than one day), was observed in only 15 of the 181 deaths $(8 \%)$.

In this study, we only examined the occurrence of waiting list related deaths to understand better the hazards of waiting for cardiac surgery and ultimately to help in decision making about health care policy. However, the quality of life while waiting for surgery was not considered even though this represents another aspect of health care policy. Quality of life in this situation may be compromised because of anxiety, the fear of complications and the functional condition of the patient. ${ }^{14}$

Finally, although certain aspects of our study are specific to the Dutch situation, we believe that the broad conclusions from this study are valid for any country in which the availability of cardiac surgery is restricted by budgetary constraints. For example, the issue of determining suggested waiting times for one particular priority group relative to suggested waiting times for other priority groups is to be found in all waiting list situations where the degree of urgency may vary from person to person.

In summary, while waiting lists are necessary for the efficient use of expensive medical procedures such as cardiac surgery, it is unethical to withhold treatment that can prolong life. One ethically acceptable strategy is "risk equalisation"-to ensure that all persons waiting for surgery experience the same risk of a waiting list related death. If two parallel health care sectors exist, public (for example, National Health Service) and private, risk equalisation both within a sector and between the sectors may be considered. ${ }^{15}$ The second strategy is "risk minimisation"- to reduce planning reserve to the absolute minimum but simultaneously maintain full use of operating capacity. According to the results of this study, a planning reserve of six weeks would have avoided only half of the waiting list related deaths.
The following centres and investigators collaborated in this study: Academic Medical Center, Amsterdam (L Eijsman, JJ Kloek), Hospital De Klokkenberg, Breda (GJ Kootstra), University Hospital Groningen (T Ebels, TW Waterbolk), University Hospital Maastricht (OCKM Penn, ThWO Elenbaas), University Hospital Nijmegen (LK Lacquet, G Kaan ${ }^{\dagger}$ ), University Hospital Utrecht (JJ Bredée, SR Woolley), Catharina Hospital, Eindhoven (E Berreklouw), University Hospital Leiden (HA Huysmans, MIM Versteegh), St Antonius Hospital, Nieuwegein (FEE Vermeulen, JJAM Defauw), University Hospital wegein (FEE Vermeulen, JJAM Defauw), University Hospital
Dijkzigt Rotterdam (E Bos, RB Hokken), and Hospital De Dijkzigt Rotterdam (E Bos, RB Hokken), and Hospital De
Weezenlanden, Zwolle (MMP Haalebos, EP de Kluiver). ${ }^{\dagger}$ Deceased

1 Suttorp MJ, Kingma JH, Vos J, et al. Determinants for early mortality in patients awaiting coronary artery bypass graft surgery: a case-control study. Eur Heart $\mathcal{F}$ 1992;13:238-42.

2 Naylor CD, Sykora K, Jaglal SB, et al. Waiting for coronary artery bypass surgery: population-based study of 8517 consecutive patients in Ontario, Canada. Lancet 1995;346: consecutive 1605 .

3 Begeleidingscommissie Hartchirurgie Nederland. Overview: cardiovascular procedures, 1994. The Netherlands. Cardiologie 1995;2:265.

4 Juul-Möller S, Edvardsson N, Jahnmatz B, et al. Doubleblind trial of aspirin in primary prevention of myocardial infarction in patients with stable chronic angina pectoris. infarction in patients with

5 Billing JS, Arifi AA, Sharples LD, et al. Heart surgery in UK patients: planned care or crisis management? Lancet 1996; 347:540-41.

6 Silber S, Muhling H, Dorr R, et al. Waiting times and death on the waiting list for coronary artery bypass operation. Experiences in Munich with over 1,000 patients. Herz 1996;21:389-96.

7 van Domburg R. Long-term survival and predictors of mortality in coronary heart disease [dissertation]. Rotterdam (Netherlands): Erasmus University, 1998.

8 Laird-Meeter K, Penn OC, Haalebos MM, et al. Survival in 1041 patients with consecutive aorto-coronary bypass operations. Eur Heart 7 1984; 5:35-42.

9 Heart Council of the Netherlands: Cardiac Surgery and Interventional Cardiology Committee. Heart surgery and interventional cardiology for adults. The Hague (Netherlands): Health Council of the Netherlands, 1995: 86-9.

10 Kee F, McDonald P, Gaffney B. Prioritising the cardiac surgery waiting list: the angina patient's perspective. Heart 1997;77:330-2

11 Cox JL, Petrie JF, Pollak PT, et al. Managed delay for coronary artery bypass graft surgery: the experience at one Canadian center. F Am Coll Cardiol 1996;27:1365-73.

12 Hadorn DC, Holmes AC. The New Zealand priority criteria project. part 1: overview. $B M F$ 1997;314:131-4

13 Hadorn DC, Holmes AC. The New Zealand priority criteria project. part 2: coronary artery bypass graft surgery. BMF 1997;314:135-8

14 Underwood MJ, Firmin RK, Jehu D. Aspects of psychological and social morbidity in patients awaiting coronary artery bypass grafting. Br Heart $\mathcal{F}$ 1993;69:382-4.

15 Marber M, MacRae C, Joy M. Delay to invasive investigation and revascularisation for coronary heart disease in south west Thames region: a two tier system? BMF 1991;302:1189-91. 